\title{
A Utilização do Geogebra na Demonstração Matemática em Sala de Aula: o estudo da reta de Euler
}

\section{The Use of Geogebra in Mathematical Proof in the Classroom: studying the Euler line}

\author{
Nélia Amado* \\ Juan Sanchez ${ }^{* *}$ \\ Jorge Pinto $^{* * *}$
}

\begin{abstract}
Resumo
Neste artigo adotamos uma perspetiva de demonstração como forma particular de argumentação matemática. O estudo apresentado envolve uma experiência de ensino no $9 .^{\circ}$ ano, na qual foram tratadas propriedades do triângulo e seus pontos notáveis. Este estudo segue uma metodologia qualitativa, de carácter interpretativo. Os dados provêm de observação participante, gravações de áudio e vídeo das aulas, produções dos alunos com papel e lápis e no computador e de entrevistas. A partir de figuras construídas no Geogebra, os alunos estruturaram ideias matemáticas e raciocínios e construíram cadeias argumentativas. Os dados analisados mostram que a maioria dos alunos formula e explora conjeturas, procurando caminhos para a sua justificação. Os alunos reconhecem a importância do Geogebra na sua atividade como fator motivador e, acima de tudo, por permitir experimentar e manipular figuras. Os resultados apontam a importância da atividade com o Geogebra, na construção e manipulação como ponto de partida para a demonstração.
\end{abstract}

Palavras-chave: Demonstração. Geometria. Geogebra. Triângulo. Reta de Euler.

\begin{abstract}
In this study, we adopt a perspective of proof as a particular form of argumentation in mathematics. The study involves an experiment developed with 9th grade students, in which activities related to the triangle and its centres were proposed and carried out. This study follows a qualitative methodology of interpretative nature. Data were collected through participant observation, audio and video recordings of classes, student productions with paper and pencil, and with computers and interviews. Starting with the construction of figures in Geogebra,
\end{abstract}

\footnotetext{
* Doutora em Matemática, na especialidade de Didática da Matemática pela Universidade do Algarve. Professora Auxiliar da Faculdade de Ciências e Tecnologia da Universidade do Algarve, Portugal. Endereço para correspondência: Faculdade de Ciências e Tecnologia da Universidade do Algarve, Campus de Gambelas, CEP: 8005-139, Faro, Portugal. E-mail: namado@ualg.pt

** Doutor em Matemática, na especialidade de Análise Matemática pela Universidade do Algarve. Professor Auxiliar na Faculdade de Ciências e Tecnologia da Universidade do Algarve, Portugal. Endereço para correspondência: Faculdade de Ciências e Tecnologia, Universidade do Algarve, Campus de Gambelas, CEP: 8005-139 Faro, Portugal. E-mail: jsanchez@ualg.pt

*** Mestre em Didática da Matemática pela Universidade do Algarve. Professor de Matemática do Ensino Básico e Secundário, Faro, Portugal. Endereço para correspondência: Rua Dr. José Filipe Álvares, 12, 4. ${ }^{\circ}$ Esq., CEP: 8005-221, Faro, Portugal.E-mail: jorge_pinto2@sapo.pt
} 
students structured their mathematical reasoning and ideas and built argumentative chains, which led to proving. The data show that most students were able to explore and formulate conjectures as a path leading to proving. Students recognized the importance of Geogebra as motivating but mainly for allowing experimenting and manipulating figures. The results point to the importance of the activity with Geogebra in construction and manipulation as a springboard to proof.

Key-words: Proof. Geometry. Geogebra. Triangle. Euler Line.

\section{Introdução}

A demonstração é considerada a base da compreensão em Matemática e é essencial para desenvolver, criar e comunicar o conhecimento matemático (STYLIANIDES; STYLIANIDES, 2008). Assim, a sua introdução tardia na sala de aula pode originar dificuldades na forma de pensar dedutivamente, tanto em tarefas que pressupõem raciocínio dedutivo quer noutras tarefas matemáticas. Neste sentido, vários investigadores defendem que a demonstração deve fazer parte da experiência de todos os alunos e estar presente em todos os níveis de ensino (NCTM, 2000; HANNA, 1995; STYLIANIDES; STYLIANIDES, 2008).

Yang (2011) acrescenta que as dificuldades dos alunos podem surgir logo no momento da leitura do enunciado de uma tarefa de demonstração, o que pode dificultar ou mesmo inviabilizar a formulação de conjeturas e a construção da demonstração. Desta forma, Yang defende que os alunos devem começar pelas figuras, por entender os termos, os conceitos e os símbolos matemáticos para efetivamente perceberem o que se pretende demonstrar. Neste contexto, as novas tecnologias, em particular o computador e os ambientes de geometria dinâmica, podem dar um importante contributo. É reconhecido que as tecnologias vieram transformar o ensino da Matemática, permitindo novas formas de abordar e explorar os problemas geométricos. Os ambientes de geometria dinâmica atualmente existentes possibilitam a construção e a manipulação das figuras, com rigor e rapidez, envolvendo os alunos mais ativamente na realização das tarefas que têm por base a análise de propriedades e relações geométricas. Um das grandes vantagens proporcionadas pelas tecnologias e, em particular, pelo Geogebra, é permitir que os alunos adquiram novos conhecimentos que de outra forma dificilmente estariam ao seu alcance pelo elevado grau de abstração que exigiriam na ausência de meios de teste e experimentação (SANTOS-TRIGO, 2007). Vários estudos mostram que o recurso ao Geogebra pode trazer importantes benefícios, ao permitir, de uma forma mais ou menos intuitiva, construir e explorar figuras, formular conjeturas e relacionar propriedades que se evidenciam durante o processo de manipulação (NCTM, 2000). A este propósito, Lopes (2013) destaca as potencialidades da utilização do Geogebra na realização de 
tarefas de investigação em trigonometria principalmente pela possibilidade de construção, pelo dinamismo, pela maior oportunidade de investigação, de visualização e de criação de argumentos matematicamente válidos.

Importa pois compreender como é que os alunos relacionam conceitos geométricos e utilizam raciocínios matemáticos nas suas justificações, a partir das propriedades que são evidenciadas pelas figuras produzidas e exploradas num ambiente de geometria dinâmica.

Neste artigo procura-se saber como é que alunos do Ensino Básico mobilizam e estruturam ideias matemáticas, raciocínios lógico-dedutivos e como os relacionam através de cadeias argumentativas que visam demonstrar propriedades relacionadas com os pontos notáveis do triângulo. A demonstração matemática será encarada, não numa perspectiva formal, que pouco significado teria para os alunos deste nível de escolaridade, mas como produto decorrente de uma justificação que encerra o carácter geral do universo matemático, ou de um contraexemplo que demonstra a falta de validade de uma afirmação ou conjectura. As justificações de ideias matemáticas são pois formuladas pelos alunos quando estes se encontram face à concretização de tarefas de natureza investigativa. Esta perspectiva de continuidade entre a argumentação e a demonstração é defendida por diversos investigadores, designadamente por Boavida (2005). Neste artigo adotaremos esta perspectiva de demonstração que a coloca como uma forma particular de argumentação.

Seguindo as recomendações de Yang (2011), os alunos, a partir da construção de figuras no Geogebra, poderão estruturar os seus raciocínios e potenciar a utilização da lógica dedutiva através da visualização de figuras e análise das suas propriedades, enquanto estruturas dinâmicas. Desta forma, procura-se responder à seguinte questão abrangente: Qual o poder que a tecnologia confere à demonstração e de que forma o trabalho no Geogebra potencializa o raciocínio lógico-dedutivo?

\section{Enquadramento teórico}

\subsection{A importância da demonstração no ensino/aprendizagem da Matemática}

Durante décadas, a demonstração surgiu particularmente associada ao ensino da geometria, sendo encarada como algo a ser memorizado, constituindo uma matéria de estudo obrigatório para exame final (PONTE; MATOS; ABRANTES, 1998). Nessa época, a demonstração não partia de conjecturas construídas pelos alunos; no entanto, esta visão tem 
vindo progressivamente a ser abandonada. Balacheff (2002) considera que não há presentemente um consenso na comunidade de educação matemática sobre o que constitui uma prova ou o que deve ser objeto de investigação em relação à prova, mas parece existir desde há muito uma clara defesa da sua relevância em qualquer currículo de Matemática (COBB; WOOD; YACKEL, 1993; PONTE; MATOS; ABRANTES, 1998).

Nas últimas décadas, o surgimento das novas tecnologias veio permitir uma nova abordagem da Matemática, que possibilita a realização de experiências, a formulação de conjeturas e a obtenção de novo conhecimento. Atualmente, os alunos podem e devem combinar o trabalho apoiado no uso de tecnologias com o trabalho baseado em papel e lápis (ARTIGUE, 2002; KIERAN, 2007), de modo a construírem uma aprendizagem assente numa compreensão mais profunda e sólida dos conceitos, que possa ser geradora de maior motivação, autoestima e empenhamento (HENNESSY; RUTHVEN; BRINDLEY, 2005). O computador permite que os alunos experimentem e usem a sua intuição na descoberta e na formulação de conjeturas para que, numa fase posterior, construam processos demonstrativos com papel e lápis. Deste modo, ao justificarem as suas afirmações e, consequentemente fazerem uso de um raciocínio argumentativo, os alunos podem convencer-se e convencer os outros da veracidade das suas afirmações.

Em relação ao significado da prova, Pietropaolo (2005), num estudo feito com educadores matemáticos, revela uma preocupação para que se faça um trabalho na sala de aula de acordo com as capacidades intelectuais dos alunos. De acordo com este autor "os conteúdos curriculares não podem estar fora das capacidades intelectuais dos alunos, sendo necessário portanto, pensar e pesquisar alternativas para superar dificuldades e chegar inclusive às provas formais" (p. 210). A prova deve ser repensada como um "processo de exploração, de procura de conjecturas, de contra-exemplos, de refutação, de aplicação e de comunicação e não com o sentido formalista que a caracterizou nos currículos praticados noutros períodos (PIETROPAOLO, 2005, p. 212).

No plano internacional, a síntese explicativa sobre a norma reasoning and proof estipulada pelo NCTM (2000) refere que todos os alunos devem ter oportunidade de "reconhecer o raciocínio e a prova como aspectos fundamentais da Matemática; formular e investigar conjecturas matemáticas; desenvolver e avaliar argumentos matemáticos e provas; [e] seleccionar e usar vários tipos de raciocínio e métodos de prova” (p. 56).

Veloso (1998) invoca duas razões para a demonstração matemática estar presente na aula de Matemática: (a) aprender a raciocinar e (b) compreender a natureza da Matemática. 
Este autor defende que trabalhar a demonstração na aula de Matemática, quer no contexto de realização de investigações, quer analisando certas demonstrações, particularmente no Ensino Secundário, contribui para que os alunos aprendam a raciocinar. Considerando que não é indispensável a demonstração para que os alunos adquiram estas estruturas básicas de raciocínio, adverte que sem passarem pela demonstração os alunos não irão interiorizar, compreender e apreciar a natureza da Matemática. Veloso (1998) defende ainda que

Os alunos devem chegar ao ensino secundário com uma experiência já considerável de actividades de investigação em matemática, durante a qual tiveram numerosas ocasiões para argumentar e demonstrar, e reflectir com a ajuda do professor sobre essa experiência matemática (p. 362).

As atividades de investigação levam, em muitos casos, à necessidade de validar resultados provenientes de conjeturas, de intuições ou simplesmente de observações. Tanto no Ensino Básico como no Secundário, as demonstrações devem ser rigorosas e conter algum simbolismo, mas não tornar-se demasiado formais, devendo privilegiar-se o raciocínio lógicodedutivo e as cadeias argumentativas. Desta forma, e quando adequadas ao nível de escolaridade e ao contexto de ensino, poderão possibilitar a compreensão da Matemática. É também fundamental que constituam para o aluno um instrumento a ser usado para fazer Matemática (no sentido da produção de conhecimento que esteja ao seu alcance) e não apenas um mero objeto de apreensão e de memorização. Assim, a demonstração deve assumir um carácter pedagógico, sendo também uma forma de educar os alunos para que estes se sintam cada vez mais seguros e motivados nas suas argumentações matemáticas.

\subsection{Prova e demonstração: que diferenças?}

As palavras demonstração e prova são frequentemente utilizadas de forma indistinta. Esta situação que surge em particular na língua portuguesa não se coloca na literatura anglófona onde a palavra proof parece ser suficiente, embora alguns autores apresentem as variantes de mathematical proof e formal proof (PIETROPAOLO, 2005).

Balacheff (2002) admite que, em educação, não existe consenso acerca do que é exatamente prova e demonstração e defende a importância de distinguir estes dois conceitos. Para este autor, a prova é como uma explicação aceite por uma comunidade, sendo reconhecida pela mesma como convincente. A demonstração, por seu lado, é o único tipo de prova aceite pelos matemáticos, respeitando regras dedutivas e indutivas que são trabalhadas sobre objetos matemáticos teóricos, usando uma linguagem formal e rigorosa. Também 
Godino e Recio (1997) e Hersh (1997) distinguem prova de demonstração. A prova é vista como uma cadeia de argumentos que permitem chegar a uma conclusão, através de raciocínios lógico-dedutivos, enquanto a demonstração utiliza uma linguagem formal como requisito de rigor.

Para Hanna (1996), demonstração é um argumento transparente usado para validar uma afirmação, com uma dupla função: a de promover a compreensão e a de convencer. A construção de uma demonstração tem a particularidade de almejar ser compreendida pelos outros. Como tal, é necessário ter em conta a quem se destina, dependendo assim a necessidade de explicitar mais ou menos, certos passos.

A função deste tipo específico de atividade foi vista, em dado momento, como dizendo exclusivamente respeito à verificação da correção das afirmações matemáticas (DE VILLIERS, 2001). A ideia de que a demonstração é usada principalmente para remover a dúvida pessoal ou a de céticos, dominou unilateralmente a prática de ensino e a maior parte das discussões ou da investigação relativa ao ensino da demonstração (DE VILLIERS, 2001). Kline (1973) já alegava, porém, que uma demonstração apenas tem significado quando responde às dúvidas dos alunos, isto é, quando prova o que não é óbvio. Segundo este autor, a necessidade de demonstrar só poderá emergir em situações em que os alunos têm incertezas quanto à verdade das proposições matemáticas.

Em Educação Matemática, a demonstração passa também por testar hipóteses, aceitar ou refutar conjeturas, levar os alunos a sentir a necessidade de validar resultados e, consequentemente, de estes serem aceites pelo grupo. Portanto, na sala de aula de Matemática, assume um papel que a torna estreitamente ligada à compreensão e a comunicação da Matemática. Hersh (1997) distingue também o papel da demonstração na investigação matemática (o de convencer) daquele que deve ser o papel da demonstração na sala de aula (o de explicar). Este autor argumenta que, na aula de Matemática, os alunos ficam facilmente convencidos e não precisam da demonstração para esse efeito; precisam dela para explicar e compreender porque é que um teorema é verdadeiro. A função de explicação parece assumir uma posição de destaque, neste contexto, pois uma demonstração que ajude a clarificar o motivo pelo qual um resultado é válido, ou não, contribui certamente para uma compreensão do mesmo (ABRANTES, SERRAZINA; OLIVEIRA, 1999; DE VILLIERS, 1999, 2001).

Veloso (1998) defende que "imitar a actividade dos matemáticos" é um pressuposto indispensável no processo de ensino e aprendizagem: 


\begin{abstract}
se um dos objetivos principais do ensino da matemática nos ensinos básico e secundário é permitir aos alunos adquirir uma compreensão viva do que é a matemática, incluindo a sua relevância, evolução histórica e características no momento presente - é indispensável que os alunos experimentem e interiorizem o carácter distintivo da matemática como ciência, ou seja a natureza do raciocínio dedutivo e mesmo a estrutura axiomática das suas teorias.

Com efeito, a matemática não é uma ciência experimental. As suas teorias e as 'verdades' que elas afirmam - que têm um carácter relativo - não se constroem nem se comprovam pela repetição de experiências, mas pela demonstração (1998, p. 360$361)$.
\end{abstract}

Desta forma, a demonstração não deve ser vista como um fim, mas como um meio para promover o processo de ensino e aprendizagem, sendo da responsabilidade do professor a apresentação de tarefas que promovam aprendizagens em contextos favoráveis à discussão de ideias e à formulação de conjeturas.

De acordo com Abrantes, Serrazina e Oliveira (1999, p. 85), "fazer conjeturas e testar hipóteses são actividades que devem preceder o desenvolvimento de abordagens formais. Em muitas situações, os alunos conseguem fazer demonstrações que estão adequadas ao seu nível etário".

A comunicação dos seus argumentos lógicos, especialmente por escrito, parece ser uma tarefa complicada, corroborando a perspectiva de Hoyles e Küchemann (2002) de que a aprendizagem da prova dedutiva em Matemática é complexa e de que o seu progresso não é linear e livre de dificuldades.

\title{
2.2 O poder das figuras na resolução de problemas geométricos
}

As figuras cumprem uma função heurística na resolução de problemas de geometria, mas o exercício dessa função não surge espontaneamente, requer um treino consciente que permita ao sujeito ter uma coordenação de diferentes maneiras de apreender as figuras. Duval (1995) refere que uma figura pode ser cognitivamente apreendida de quatro maneiras diferentes: aprendizagem perceptiva, aprendizagem sequencial, aprendizagem discursiva e aprendizagem operativa.

Embora os sujeitos ponham em jogo uma interação completa destas maneiras de apreender a figura, num processo de resolução de problemas geométricos, a aprendizagem operativa é a mais produtiva e admite e requer processamentos mais completos. A aprendizagem operativa depende de várias transformações que se realizam na figura quer externamente (fisicamente), quer mentalmente. Para Duval (1999), a reconfiguração 
desempenha um papel importante, sendo um tipo de apreensão operativa que consiste em distinguir e reagrupar os elementos ou subfiguras de uma figura dada. São várias as ações que se podem levar a cabo numa reconfiguração; por exemplo, em muitos problemas uma figura pode conter as subfiguras úteis para obter a solução e nestes casos o que se pretende é distinguir essas subfiguras do conjunto; noutros problemas devem-se construir essas subfiguras com a ajuda de traços auxiliares.

De entre as figuras geométricas existentes, os triângulos constituem um conjunto repleto de potencialidades para apreciar e estudar propriedades geométricas fundamentais. Fazem parte do universo dos alunos desde os primeiros anos de escolaridade, acompanhandoos ao longo do seu percurso escolar. Apesar de serem polígonos simples, são da maior relevância no estudo da geometria. São figuras rígidas na medida em que não se podem deformar sem se modificar o comprimento dos seus lados. Um resultado particularmente importante, que mostra a importância desta figura desde as aprendizagens iniciais, é o fato de qualquer polígono regular, ou não, poder ser decomposto em triângulos. A resolução de muitos problemas geométricos passa pela comparação de triângulos e demonstração de algumas das suas propriedades. Os ambientes de geometria dinâmica e, em particular, o Geogebra permitem o movimento das figuras e a conservação das suas propriedades, fazendo emergir conjeturas e sendo um estímulo para novas demonstrações. É esse o caso quando se trata de estudar os pontos notáveis do triângulo e algumas das suas propriedades e resultados que delas se deduzem. Aqui começa a entrar em funcionamento de forma muito saliente o raciocínio dedutivo e o tipo de trabalho que conduz à prova. A geometria é um dos campos mais férteis para o desenvolvimento de diferentes formas de raciocínio, em especial o dedutivo. No entanto, como Duval (1999) defende, o raciocínio dedutivo tem de ser parte de uma prática equilibrada na qual vários processos são essenciais, como é o caso da visualização:

\begin{abstract}
A Geometria, mais do que outras áreas da Matemática, pode ser usada para desenvolver diferentes formas de raciocínio. Este deve ser um objetivo essencial do ensino da Geometria. Mas ainda é preciso conseguir uma prática mais compreensiva e equilibrada dos processos cognitivos subjacentes. Isto quer dizer que são necessárias situações específicas de aprendizagem para a diferenciação e coordenação dos diversos tipos de visualização e raciocínio (p. 51).
\end{abstract}

\title{
2.3 O papel do computador na demonstração em Geometria
}

De Villiers (1997), aborda a relação que os alunos estabelecem com a demonstração quando desenvolvem atividades investigativas com recurso ao computador: 


\begin{abstract}
Apesar da maior parte dos alunos parecer não precisar de mais nada para ter convicções quando exploram conjecturas em ambientes geométricos dinâmicos como o Cabri ou o Sketchpad, não é difícil estimular a sua curiosidade perguntandolhes por que é que eles pensam que um determinado resultado é verdadeiro. São desafiados a tentar explicá-lo. Os alunos rapidamente admitem que a verificação indutiva/experimental apenas confirma; não esclarece nem contribui para uma compreensão satisfatória. Eles parecem desejar então procurar argumentos dedutivos como uma tentativa de explicação, mais do que uma verificação. (p. 23)
\end{abstract}

A criação de figuras em ambientes de geometria dinâmica, como o Geogebra, é um fator promotor de conhecimento, na medida em que durante a construção os alunos estão a utilizar conceitos geométricos, permitindo que as figuras mantenham as propriedades durante a manipulação e desta forma observam resultados que se tornam invariantes e formulam conjeturas.

Dado o tópico escolhido neste estudo - os triângulos e seus pontos notáveis - o uso do Geogebra revela-se uma ferramenta muito útil na construção dos triângulos e de todas as linhas inerentes à construção dos pontos notáveis, tais como: mediatriz de um segmento de reta, bissetriz de um ângulo, altura de um triângulo. Permite ainda medir comprimentos de segmentos de reta, amplitudes de ângulos e representar de forma rápida circunferências, aspectos essenciais ao estabelecimento de conjeturas. O computador é usado como um meio de visualização/verificação e exploração das figuras, permitindo identificar propriedades relacionadas com estes pontos, ajudando os alunos a formular conjeturas e a testar resultados.

Garry (2003) e Keyton (2003) defendem que os ambientes dinâmicos tornam possível executar um grande número de experiências num curto espaço de tempo, em tarefas de investigação, favorecendo a formulação de conjeturas, através de uma observação atenta sobre o que permanece constante em relação a tudo o que varia. Noutros casos, o aparecimento de contraexemplos ajuda a refutar conjeturas pré-estabelecidas. O facto de não surgirem contraexemplos contribui para que os alunos se convençam da veracidade de um resultado, tornando-se então essencial, que daí resulte o desafio de perceber a razão dessa veracidade (DE VILLIERS, 1999, 2001).

Se manipular figuras e perceber que os pontos notáveis de um triângulo continuam a verificar certas propriedades parece ser, para os alunos, uma prova irrefutável, ou seja, se aquilo que o computador mostra é verdade, então a demonstração matemática surge como um meio natural que permite a compreensão e explicação de tais resultados. A demonstração não é, neste contexto, um requisito necessário para convencer os alunos da verdade, mas um meio para a compreensão de resultados matemáticos. 
Um dos aspectos que merece particular destaque no trabalho com o Geogebra são as figuras que se obtêm em contraposição com as atividades geométricas apenas levadas a cabo com lápis e papel. Facilmente se podem adivinhar as dificuldades de compreensão que podem surgir quando os alunos tomam como referência um desenho e não uma figura. Um ambiente de geometria dinâmica permite superar definitivamente essas dificuldades. As figuras ou construções feitas em ambientes de geometria dinâmica comportam-se de acordo com as leis da geometria, isto é, refletem todas as consequências teóricas das propriedades que as definem. Por exemplo, quando se constrói um triângulo e as suas medianas, ao arrastar um vértice para transformar o triângulo, a série de figuras que surgem são triângulos e arrastam consigo as medianas mantendo-as como tais. Assim, para cada figura são válidas as propriedades que derivam da teoria como, por exemplo, que as medianas são concorrentes e se cortam na razão de dois para um. Estas aprendizagens tornam-se mais significativas e mais fáceis de obter com o recurso a um ambiente de geometria dinâmica.

\section{Metodologia}

Este estudo tem como principal objetivo compreender de que forma o trabalho com o Geogebra é um meio impulsionador e facilitador da atividade de demonstração de propriedades relacionadas com pontos notáveis do triângulo. Uma metodologia qualitativa de natureza interpretativa revelou-se a opção mais adequada ao estudo. Stake (2009) refere que as investigações de natureza qualitativa estão predominantemente orientadas para o que se passa no terreno, pois permitem uma descrição densa, através de narrativas que fornecem ao leitor muita informação acerca da experiência realizada. Assim, possibilitam uma compreensão experiencial dos fenômenos estudados, uma vez que permitem "estabelecer uma compreensão empática com o leitor através da descrição" mas que transmite "ao leitor o que a própria experiência transmitiria" (STAKE, 2009, p. 54). É neste sentido que Geelen (2007) defende que "as narrativas acerca das aulas são poderosas porque têm em conta não só as práticas correntes e as situações, mas também, as experiências passadas dos professores e as suas futuras aspirações" (p. 140).

\section{$3.1 O$ contexto de investigação}


O tema do triângulo, suas propriedades e pontos notáveis, é particularmente adequado ao Ensino Básico, razão pela qual se optou por trabalhar com alunos de uma turma de $9 .^{\circ}$ ano (14-15 anos). A seleção da escola para realizar uma experiência de ensino foi feita de acordo com a existência de salas com computadores e a escolha da turma foi ditada por conveniência, em termos de horário de funcionamento das aulas. A experiência de ensino decorreu numa turma de 20 alunos, dos quais apenas oito se disponibilizaram a participar neste estudo. A sala onde decorreu a experiência dispunha de 5 computadores, o que permitiu colocar os alunos a trabalhar em pares em cada computador. Estes alunos nunca tinham tido oportunidade de usar o computador na sala de aula.

Para a recolha de dados foram respeitados todos os procedimentos éticos recomendados, tais como solicitadas as autorizações, explicados os objetivos do estudo, garantida a confidencialidade e reserva dos dados ao estudo a realizar. Pelas razões referidas os nomes adotados são fictícios.

Neste estudo foram recolhidos dados provenientes de diferentes fontes: para além da observação participante, recorreu-se ainda a entrevistas e à recolha de documentos produzidos pelos alunos nas atividades propostas, tal como é recomendado por vários autores (STAKE 2009, BOGDAN; BIKLEN, 1994).

Foram realizadas seis sessões semanais com a duração de 90 minutos cada. Nestas sessões estiveram sempre presentes o investigador e o professor da turma, que partilharam o trabalho conduzido na aula e as interações com os alunos. Na primeira sessão foi realizada uma revisão sobre o triângulo e alguns dos seus segmentos e pontos notáveis. Os critérios de semelhança de triângulos, estudados em anos anteriores, também foram recordados, tal como as definições de altura, mediatriz e mediana.

\section{Apresentação dos dados}

\subsection{A reta de Euler}

Para este artigo selecionamos a quinta tarefa proposta - Reta de Euler, cujo principal objetivo é relacionar os três pontos notáveis do triângulo: baricentro, circuncentro $e$ ortocentro. A opção por esta atividade deve-se ao facto de envolver os pontos tratados nas primeiras sessões, o que possibilita conhecer e compreender como é que os alunos relacionam estes conhecimentos numa nova cadeia argumentativa. 
Após a construção de um triângulo e dos três pontos notáveis no Geogebra, foi pedido aos alunos que analisassem a figura e investigassem o que havia de especial relativamente a estes pontos (baricentro, circuncentro e ortocentro).

Professor: Quais são os pontos que vos parecem estar alinhados? Vamos lá selecionar uma reta no menu "reta definida por dois pontos".

Carla: São estes três.

Professor: A reta passa ou não por esses três pontos?

Carla: Passa. Eu adoro o Geogebra! O Bernardo, se pudesse, estava 24 horas no Geogebra. (Gravação áudio-visual, 2010)

Através da construção dos três pontos, da observação e manipulação da figura, os alunos concluíram que estavam alinhados numa reta (Figura 1). Em seguida foi dada a informação: "Estes pontos estão alinhados numa reta a que se dá nome de reta de Euler".

Carla: É um baralhar de linhas. Quando é que a gente chega à reta de Euler? É este picotado?

Catarina: Sim, é esse picotado. (Gravação áudio-visual, 2010)

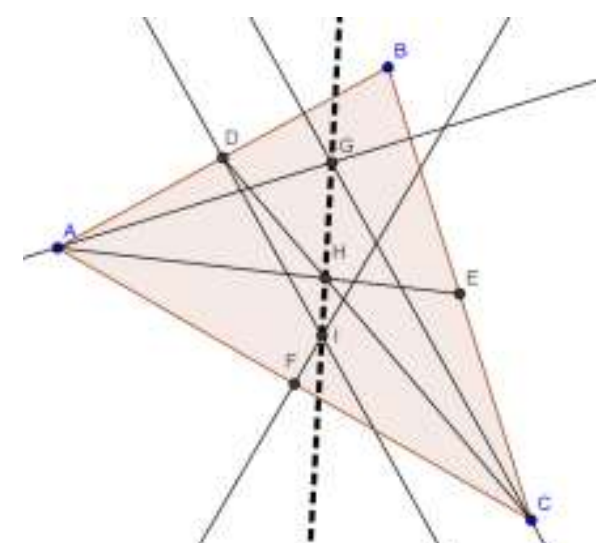

Figura 1 - Imagem da figura construída pelos alunos no Geogebra

Fonte: dados de pesquisa (2010)

Traçada a reta de Euler, foi sugerido que tentassem encontrar outras propriedades.

Verificando-se que os alunos estavam com dificuldades, foi sugerido que analisassem as distâncias entre os pontos.

Professor: Qual é o ponto que vos parece estar ao dobro da distância do outro?

Catarina: Então, é o... IH é metade de $H G$.

Professor: Identifiquem esses pontos, eles têm nome. (Gravação áudio-visual, 2010)

A simples observação da figura permitiu aos alunos identificar, quase de imediato, a existência de uma relação entre as distâncias entre os pontos. A conjetura tornou-se mais consistente quando os alunos efetuaram as medições e, movimentando a figura, constataram que o resultado se mantinha sempre válido. Após realizarem várias experiências e medições 
no Geogebra, concluíram que a distância do ortocentro ao baricentro era o dobro da distância do circuncentro ao baricentro. Este resultado tornou-se o objetivo da demonstração.

Para ajudar os alunos, foram sugeridas algumas etapas, nomeadamente o reconhecimento e aplicação de propriedades relacionadas com triângulos semelhantes e outros resultados anteriormente demonstrados, de modo a deduzir argumentos que validassem o resultado. Esta atividade requer uma boa observação da figura e uma criteriosa justificação das sugestões; os alunos deveriam ser capazes de sistematizar todos os resultados e concluir o pretendido. Para o início da atividade foram sugeridas as seguintes indicações:

a) A distância entre dois deles é o dobro da distância entre outros dois. Quais são esses pontos?

b) Justifica que a reta $\mathrm{CG}$ e a mediatriz de $[\mathrm{AB}]$ são paralelas.

c) Considera os triângulos [HID] e [GHC]. Justifica que os triângulos são semelhantes.

d) Prova o resultado da alínea a)

Recorda: a distância de cada vértice ao baricentro é igual a 2/3 do comprimento da respetiva mediana

Quadro 1 - Enunciado da tarefa

Fonte: Dados da pesquisa (2010)

Os alunos deveriam reconhecer que os triângulos [HID] e [GHC] são semelhantes pelo critério AA, dado que o ângulo DHI e o ângulo GHC são verticalmente opostos e os ângulos IDH e HCG são ângulos de lados paralelos, porque CG e DI são ambas retas perpendiculares ao lado $[\mathrm{AB}]$. Deveriam ter em conta que o ponto $\mathrm{H}$ é também o baricentro do triângulo [ABC] e deduzir que $\overline{\mathrm{HC}}=2 \overline{\mathrm{HD}}$. Justifica-se assim que os triângulos [HID] e [GHC] são semelhantes de razão 2 e poderá concluir-se que $\overline{\mathrm{HG}}=2 \overline{\mathrm{HI}}$.

Vejamos então como procederam os alunos nesta tarefa.

\subsection{Da construção no Geogebra à demonstração com papel e lápis}

Inicialmente os alunos discutiam entre si algumas ideias e quando consideravam que elas podiam ser relevantes pediam ao professor para as registar no quadro. Por vezes, tentavam perceber através das reações dos professores se estes validavam logo as suas hipóteses, como se depreende dos diálogos seguintes.

Catarina questiona Maria:

Catarina: Olha lá! Como é que isto aqui é paralelo a isto aqui?

Maria: $O$ quê?

Catarina: Mas isto aqui não é paralelo, nem lá perto...

Bernardo: Estão frente a frente.

Carla: Estar frente a frente é paralelo? (Gravação áudio-visual, 2010) 
O professor pergunta porque é que as retas são paralelas e Catarina responde:

Catarina: Porque ambas formam um ângulo de $90^{\circ}$ com a reta $A B$.

A aluna procura justificar o paralelismo entre as duas retas com o facto de ambas serem perpendiculares à reta $\mathrm{AB}$ mas o professor procura conduzir os alunos para os casos de semelhança de triângulos.

Professor: Na última aula estiveram a ver semelhança de triângulos. Ainda se lembram?

Carla: Sim, é LLL.

Catarina: LAL e LAA são só três.

Professor: Então vejam lá se conseguem provar que os triângulos são semelhantes.

Brígida: Eu acho que já sei. Pode chegar aqui, professor?

Catarina: Eu também acho que já sei, aqui são iguais os ângulos.

Professor: Só isso não chega.

Maria: Olha! Têm dois lados paralelos, estes ângulos são iguais e têm um lado comum.

Catarina: Mas isto faz ângulos de $90^{\circ}$ para todos os lados. Oh professor chegue lá aqui, se faz favor.

Brígida: Catarina, empresta aí a tua ficha, tenho a impressão que pintaste mal aí um triângulo.

Catarina: Pois foi ... esta coisa aqui...

Carla: Professor, este ângulo é verticalmente oposto a este?

Professor: Sim.

Carla: Já está, agora não sei é como é que posso explicar! (Gravação áudio-visual, 2010)

Os alunos mostram dificuldade em transcrever as suas ideias, talvez por falta de uma linguagem matemática adequada ou por dificuldade em relacionar conceitos e expressá-los com clareza.

Esta ideia, de que o potencial dos ambientes de geometria dinâmica ajuda na formulação de conjeturas, fazendo surgir a sua justificação/explicação como algo necessário para a compreensão dos resultados, também é reconhecida por Parks (2003) ao referir:

O uso de software de geometria dinâmica encoraja-os [os alunos] a estruturar o pensamento matemático e a descobrir padrões através de exemplos. Isto leva-os a fazer conjeturas sobre os resultados e podem, em seguida, prosseguir na descoberta das justificações matemáticas que estão por trás desses resultados. (p. 119)

A construção no Geogebra por si só motiva e entusiasma os alunos, permitindo-lhes estabelecer uma relação de maior proximidade com a Matemática. O fato de se traçar uma reta que passa por um ponto e é perpendicular a outra, facilita e promove a compreensão do que são retas perpendiculares, pois o movimento da figura permite observar que todas essas propriedades se mantêm inalteradas.

As potencialidades do programa estão ao dispor dos alunos e foi com base nelas que se verificou que os três pontos estavam alinhados e que as distâncias observadas verificavam 
a referida relação métrica. Todas estas verificações aumentam o grau de certeza devido à movimentação da figura, estabelecendo-se assim uma conjetura válida.

Seguiu-se o trabalho com recurso ao papel e lápis, cabendo agora aos alunos explicar o porquê dos resultados observados no computador. Para mostrar que os triângulos eram semelhantes, os alunos, foram respondendo às questões colocadas, de forma a identificarem ângulos congruentes e triângulos semelhantes. Estas questões serviram como etapas intermédias para facilitar o estabelecimento de conexões entre resultados e assim dar início a uma cadeia argumentativa baseada em raciocínios dedutivos.

Catarina e Carla trocam, entre si, argumentos e discutem ideias:

Catarina: Só encontro um ângulo igual!

Carla: Este aqui, também não é igual a este com este? Oh professor, veja lá se isto aqui está bem.

Professor: Justifiquem porquê, não fiquem só pela observação.

Catarina: Professor, pode chegar aqui, este aqui com este são o quê?

Carla: São verticalmente opostos. Não, são de lados paralelos.

Professor: São ângulos de lados paralelos.

Carla: Oh professor, falar deles, como assim? Para dizer que são verticalmente opostos.

Catarina: Isso não chega, o que tu disseste....

Carla: Chega, chega. (Gravação áudio-visual, 2010)

A discussão entre as alunas e o professor permite clarificar ideias, estruturar raciocínios e formas de pensar que ajudam a iniciar o processo demonstrativo. Quando os alunos manifestam dificuldade em justificar certos resultados relacionados com conceitos básicos, o raciocínio dedutivo torna-se mais tortuoso e dificulta a passagem para níveis mais elevados de compreensão.

Em todo o caso, o recurso ao computador foi fundamental nesta atividade, na medida em que as figuras construídas no Geogebra ajudaram a formular conjeturas e verificar relações, funcionando como um estímulo aos alunos para a compreensão do resultado geométrico que se pretendia justificar.

Ilustraremos de seguida o trabalho realizado por uma das alunas, Carla, que efetuou grande parte da demonstração ainda que não a tenha concluído de forma plena. A aluna começou por verificar que a distância entre o circuncentro e o baricentro é metade da distância entre o baricentro e o ortocentro. Justificou também que a reta CG e a mediatriz de [AB] são paralelas, argumentando que ambas formam um ângulo de 90 graus com o lado $[\mathrm{AB}]$. Após concluir que a reta $\mathrm{CG}$ e a mediatriz de $[\mathrm{AB}]$ são paralelas era necessário justificar que os triângulos [HID] e [GHC] eram semelhantes (Figura 2). 


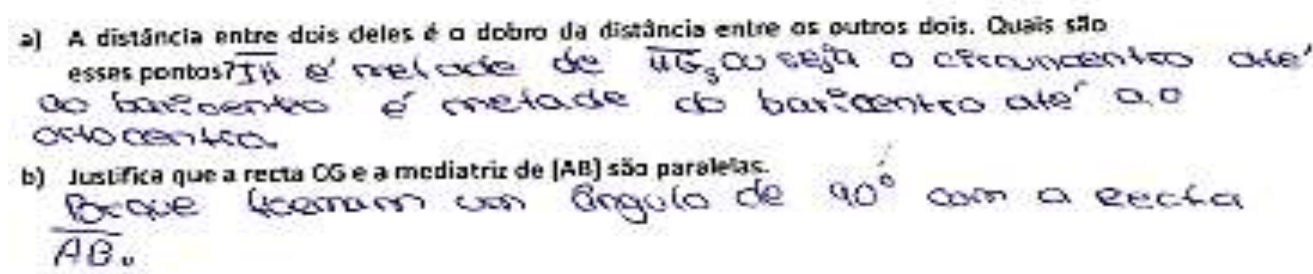

Figura 2 - Parte da resolução da tarefa com papel e lápis da aluna Carla Fonte: dados de pesquisa (2010)

A aluna começa por enunciar o critério AA (para triângulos semelhantes), concluindo que os triângulos [HID] e [GHC] têm os ângulos congruentes, mas mencionando apenas como ângulos congruentes (por serem verticalmente opostos), o ângulo DHI e o ângulo GHC (embora tenha escrito incorretamente DHC) (Figura 3). Embora a aluna tenha dado evidências de reconhecer os ângulos IDH e HCG como congruentes, não justifica essa conclusão com base no fato de serem ângulos de lados paralelos, resultante do paralelismo entre CG e DI, e que foi anteriormente justificado, mas não utilizado. A não justificação de que os ângulos são congruentes mostra que a justificação do paralelismo entre as retas não foi útil. A aluna também não mostrou curiosidade em investigar resultados associados ao fato de as retas serem paralelas.

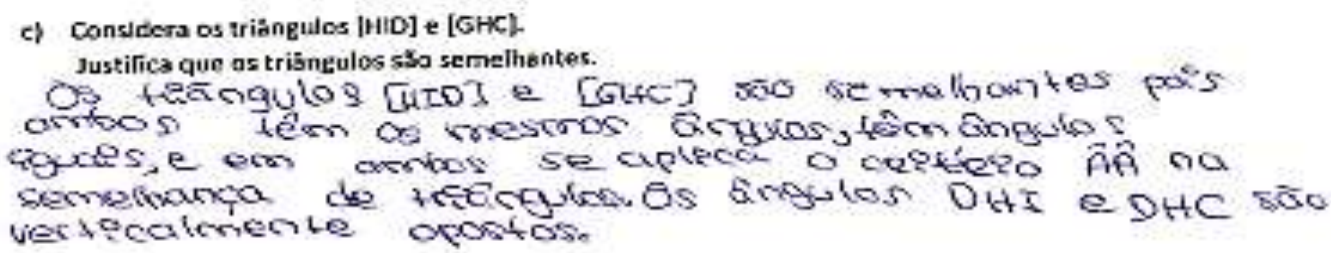

Figura 3 - Parte da resolução da tarefa com papel e lápis da aluna Carla Fonte: dados de pesquisa (2010)

A informação dada de que a distância de cada vértice ao baricentro é $2 / 3$ do comprimento da respetiva mediana, permitiu à aluna compreender que os lados $[\mathrm{HC}] \mathrm{e}[\mathrm{DH}]$ estão na razão de 2:1 pelo facto de estarem sobre uma mediana. No entanto, não lhe permitiu concluir que a distância $\overline{\mathrm{HG}}$ é o dobro da distância $\overline{\mathrm{HI}}$, como consequência da razão de semelhança ser 2 entre os triângulos [HID] e [GHC], pois afirmou que a razão de semelhança entre os triângulos era de 2/3, o que revela insuficiente compreensão do problema. Esta afirmação feita pela aluna não lhe permitiu concluir que a distância $\overline{\mathrm{HG}}$ é o dobro da distância $\overline{\mathrm{HI}}$, resultante da razão de semelhança, igual a 2, entre os triângulos [HID] e [HIC]. Ao evocar que a razão de semelhança entre os triângulos era 2/3, não justifica o pretendido (Figura 4). 
d) Prova o resultado da alinea a)

Recorda: a distância de cada vértice ao baricentro é igual a $\frac{2}{3}$ do comprimento da respectiva mediana

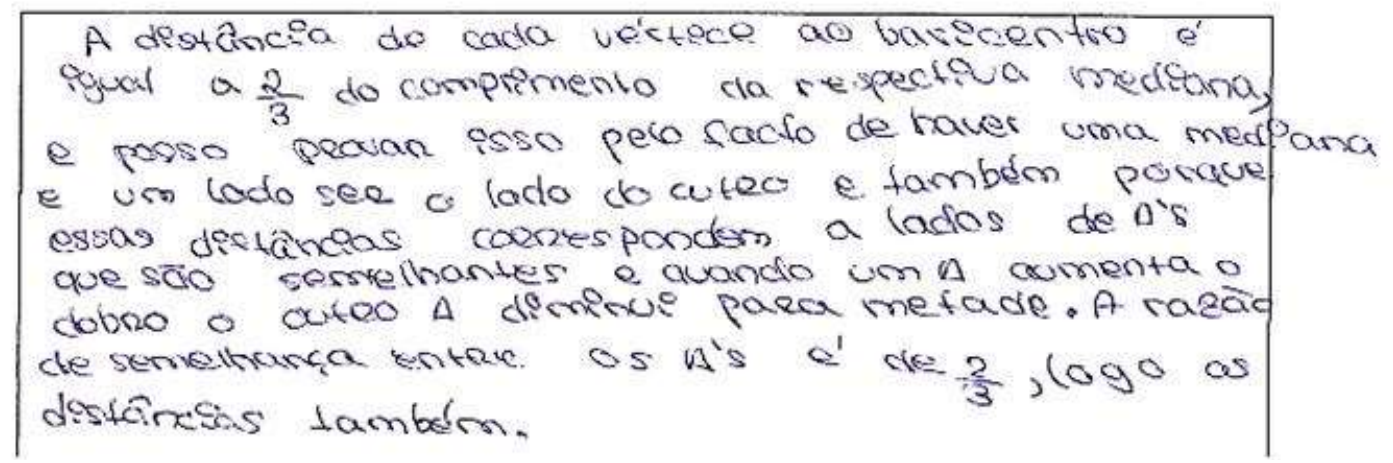

Figura 4-Imagem da última parte da demonstração Carla Fonte: dados de pesquisa (2010).

A demonstração pedida exigia dos alunos uma forte relação entre resultados que já tinham sido justificados e o resultado que se pretendia obter. A necessidade de relacionar vários resultados de forma a obter outros mostra-se, por vezes, difícil devido ao nível de abstração que requer.

Carla e Catarina, duas alunas que não conseguiram concluir com sucesso toda a tarefa de encadeamento de resultados, reconhecem, apesar disso, a importância do trabalho com o Geogebra, destacando, em especial a possibilidade de construir a figura com rigor e a vantagem de movimentarem o triângulo, o que parece ter-lhes dado maior segurança na formulação das conjeturas. A opinião da aluna é condizente com Yang (2011) ao defender a importância da utilização das figuras.

Carla: Não podíamos movimentar a figura [no papel] e com o computador podemos.

Catarina: Ajuda e é mais fácil porque temos os resultados todos e dá para mexer o triângulo e ver. (Gravação áudio-visual, 2010)

Tal como resulta dos dados, o Geogebra pode desempenhar um papel importante de iniciação à demonstração na sala de aula, em particular, no Ensino Básico, encorajando os alunos a raciocinarem dedutivamente com papel e lápis, mesmo quando construção de uma cadeia argumentativa conducente à prova é apenas parcialmente alcançada.

\section{Conclusões}

Os alunos envolvidos nesta experiência nunca tinham estado envolvidos na atividade de demonstração nem tinham tido oportunidade de trabalhar com o computador na aula de 
Matemática. O recurso ao computador e, em particular, ao Geogebra, não originou qualquer dificuldade para os alunos que, pelo contrário revelaram um grande à vontade na manipulação desta ferramenta, emergindo desse uso diversas vantagens. As palavras de Carla e Bernardo mostram o gosto e o entusiasmo em trabalhar com o Geogebra na aula de Matemática. E o mais importante, do nosso ponto de vista, é que o recurso ao computador foi determinante no desenvolvimento de uma cadeia de argumentos. A construção do triângulo e dos pontos notáveis permitiu aos alunos chegarem à reta de Euler, mas a visualização da figura e a sua manipulação contribuiu decisivamente para que os alunos formulassem conjeturas, nomeadamente em relação às distâncias entre os pontos e que estas se mantinham inalteradas quando arrastavam elementos do triângulo. Tal como refere Santos-Trigo (2007), o recurso ao Geogebra permitiu desenvolver conhecimentos que apenas o trabalho com papel e lápis não tornaria facilmente acessível nem compreensível pelos alunos; é este o verdadeiro sentido da utilização da tecnologia na aula de Matemática. Os alunos, a partir do trabalho feito no Geogebra, compreenderam qual era o objetivo que pretendiam alcançar e foram capazes de traduzir os seus raciocínios dedutivos com papel e lápis. Assim, a demonstração passou a fazer sentido e a ser entendida pelos alunos, na medida em que foram eles que formularam a conjetura fundamental. Um aspecto importante, quando os alunos iniciam esta atividade de demonstração, parece ser o estabelecimento de passos intermediários, como foi proposto nesta tarefa. Importa ainda destacar que o fato de se ter partido da construção do triângulo e dos pontos notáveis para obter a reta de Euler fez com que fossem os alunos a concluir o que era objeto de demonstração, evitando-se desse modo que os alunos se deparassem com a dificuldade referida por Yang (2011).

Convém salientar que ao longo desta experiência, os alunos depararam-se com algumas dificuldades na construção de cadeias argumentativas, mas ficou claro a importância de estimular os alunos a justificarem as suas próprias ideias e a desenvolver argumentos, claros e a usar uma linguagem adequada, como forma de compreender e expressar todo o raciocínio necessário à resolução de uma tarefa desta natureza. As justificações levam os alunos a pensar e refletir com mais cuidado quando resolvem uma atividade, mesmo que não consigam alcançar todos os resultados que se poderiam desejar.

A figura construída no Geogebra, como defende Yang (2011), revelou-se determinante para a formulação de conjeturas e para a resolução das etapas propostas na tarefa, para fomentar a comunicação e a discussão dos argumentos lógico-dedutivos, quer entre os alunos quer entre eles e os professores. Os ambientes de geometria dinâmica potencializam o 
raciocínio lógico-dedutivo, através da visualização de resultados invariantes perceptíveis pelos movimentos das figuras dinâmicas, quando estas são construídas com base nas propriedades geométricas. A construção das figuras e a sua exploração com movimentos de arrastamento permitiram deixar visíveis resultados relacionados com os pontos notáveis do triângulo. Tal como referem Garry (2003) e Keyton (2003), os ambientes dinâmicos permitem processar um grande número de experiências num curto espaço de tempo, favorecendo a formulação de conjeturas, através de observações do que permanece constante no meio de tudo o que varia.

Para atingir a compreensão matemática não basta a visualização da figura inicial ou das sucessivas figuras que se obtêm por arrastamento, é fundamental estimular os alunos para demonstrações mais formais, com caráter explicativo e incentivá-los a utilizar raciocínios dedutivos e a justificar o surgimento de novos resultados na busca da compreensão. Deste modo, podemos concluir que os ambientes de geometria dinâmica, como o Geogebra, podem constituir um forte aliado da demonstração, uma atividade fundamental para a compreensão matemática, como mostram os dados apresentados.

\section{Referências}

ABRANTES, P.; SERRAZINA, L.; OLIVEIRA, I. A Matemática na educação básica. Lisboa: Ministério da Educação, 1999.

ARTIGUE, M. Learning mathematics in a CAS environment: The genesis of a reflection about instrumentation and the dialectics between technical and conceptual work. International Journal of Computers for Mathematical Learning,Dordrecht, The Netherlands, v.7, n. ${ }^{\circ} 3$, p. 245-274, Outubro. 2002.

BALACHEFF, N. The researcher epistemology: A deadlock from educational research on proof. In: LIN, F. L. (Ed.). International conference on mathematics: understanding proving and proving to understand. Taipei, Taiwan: NCS and NUST, 2002. p.23-44 .

BOAVIDA, A. A argumentação em Matemática: Investigando o trabalho de duas professoras em contexto de colaboração, 2011, p. 995. Tese (Doutorado em Educação) - Faculdade de Ciências, Universidade de Lisboa, Lisboa, 2005.

BOGDAN, R; BIKLEN,S. Investigação qualitativa em educação. Porto: Porto Editora, 1994.

COBB, P., WOOD, T., YACKEL, E. Discourse, mathematical thinking, and classroom practice. In: FORMAN, E. A.; MINICK, N.; STONE E C. A. (Ed.). Contexts for learning: Sociocultural dynamics in children development. New York: Oxford University Press, 1993, p. 91-119.

DE VILLIERS, M. The Role of Proof in Investigative, Computer-based Geometry: Some Personal Reflections. KING, J. et al. (Ed.). Geometry Turned On - Dinamic Software in Learning, USA: MAA, 1997. p. 15- 24. 
DE VILLIERS, M. Rethinking Proof with Geometer's Sketchpad. USA: Key Curriculum Press, 1999.

DE VILLIERS, M. Papel e funções da demonstração no trabalho com o Sketchpad. Educação e Matemática, Lisboa, n. 62, p. 31-36, Março/Abril. 2001.

DUVAL. R. Geometrical Pictures, Kinds of Representation and Specific Process. In: SUTHERLAND, R.; MASON, J. (Ed.). Exploring Mental Imagery with Computers in Mathematics Education, Berlin Heidelberg: Springer Verlag, 1995. p. 142-157.

DUVAL, R. Semiosis y pensamiento humano. Registros semióticos y aprendizajes intelectuales. Cali: Universidad del Valle, Instituto de Educación y Pedagogía, 1999.

GARRY, T. The Geometer's Sketchpad na sala de aula. In: VELOSO, E.; CANDEIAS, N. (Org.). Geometria Dinâmica: selecção de textos do livro Geometry Turned On! Lisboa: APM, 2003. p. 6978.

GEELEN, D. Songs of Innocence and of Experience: Impressionist tales and secret stories of live in classrooms. In: TAYLOR, P.; WALLACE, J. (Ed.). Qualitative Research in Postmodern Times Exemplars for Science,Mathematics and Technology Educators. New York: Springer, 2007, p. 139-148.

GODINO J.; RECIO, A. Meaning of proofs in mathematics education. In CONFERENCE OF THE INTERNATIONAL GROUP FOR THE PSYCHOLOGY OF MATHEMATICS EDUCATION 21 th, 1997, Helsinki: University of Helsinkia Proceedings... Helsinki: University of Helsinkia, 1997. p. 313-320.

HANNA, G. Challenges to the importance of proof. For the Learning of Mathematics, Fredericton, NB. 15, n. 3, p. 42-49, Novembro. 1995.

HANNA, G. The ongoing value of proof. In: CONFERENCE OF THE INTERNATIONAL GROUP FOR THE PSYCHOLOGY OF MATHEMATICS EDUCATION $20^{\text {th }}, 1996$, Valencia: Universitat de Valencia, 1996. Proceedings... Valencia: Universitat de Valencia, 1996. p. 21-34.

HENNESSY, S., RUTHVEN, K., BRINDLEY, S. Teacher perspectives on integrating ICT into subject teaching: Commitment, constraints, caution, and change. Journal of Curriculum Studies, London, V. 37, n. ${ }^{\circ}$, p. 155-192, Mar-April. 2005.

HERSH, R. What is mathematics, really? New York: Oxford University Press, 1997.

HOYLES, C.; KÜCHEMANN, D. Students' understanding of logical implication. Educational Studies in Mathematics, Dordrecht, Netherlands, v. 51, n. ${ }^{\circ}$ 3, p. 193-223, Novembro. 2002.

KEYTON, M. Alunos descobrem a geometria usando software de geometria dinâmica. In: VELOSO, E.; CANDEIAS, N. (Org.). Geometria Dinâmica: seleção de textos do livro Geometry Turned On!, Lisboa: APM, 2003. p. 79-86.

KIERAN, C. Interpreting and assessing the answers given by the CAS expert: A reaction paper. The International Journal of Technology in Mathematics Education, Plymouth, UK, v. 14, n. ${ }^{\circ}$ 2, p. 103-107, Abril-Junho. 2007.

KLINE, M. Why Johnny can't add: the failure of the new math. New York: St. Martin's Press, 1973. 
LOPES, M. Sequência Didática para o Ensino de Trigonometria Usando o Software GeoGebra.

Boletim de Educação Matemática, Rio Claro, v.27. n. 46, p. 631-644, Agosto. 2013.

NCTM. Princípios e normas para a Matemática escolar. Lisboa: APM, 2007. (Tradução portuguesa da edição original de 2000).

PARKS, J. M. Identificar transformações pelas suas órbitas. In: VELOSO E.; CANDEIAS, N. (Org.). Geometria dinâmica, seleção de textos do livro Geometry Turned On! Lisboa: APM, 2003, p. 115119.

PIETROPAOLO, R. C. (Re)Significar a demonstração nos currículos da educação básica e da formação de professores de matemática, 2005. 388 f. Tese (Doutorado em Educação Matemática) Programa de Pós-graduação em Educação Matemática, Pontifícia Universidade Católica de São Paulo, São Paulo, 2005.

PONTE, J.; MATOS, J.; ABRANTES, P. Investigação em educação matemática: Implicações curriculares. Lisboa: IIE, 1998.

SANTOS-TRIGO, M. Mathematical Problem Solving: An Evolving Research and Practice Domain. ZDM, Heidelberg, v. 39, n. 5-6, p. 523-536, Julho, 2007.

STAKE, R. A Arte da Investigação com Estudos de Caso 2. ${ }^{2}$ Ed. Lisboa: Fundação Calouste Gulbenkian, 2009.

STYLIANIDES, G., STYLIANIDES, J. Proof in School Mathematics: Insights from Psychological Research into Students' Ability for Deductive Reasoning. Mathematical Thinking and Learning, Mahwah, New Jersey, v. 10, n. 2, p. 103-133, Abril, 2008.

VELOSO, E. Geometria - Temas Actuais. Lisboa: Instituto de Inovação Educacional, 1998.

YANG, K. Structures of Cognitive and Metacognitive Reading Strategy Use for Reading Comprehension of Geometry Proof. Educational Studies in Mathematics, Heidelberg, Germany, v. 80, n. ${ }^{\circ}$ 3, p. 307-326, Setembro, 2011.

Este trabalho foi desenvolvido no âmbito do Projeto Problem@Web, N. ${ }^{\circ}$ PTDC/CPECED/101635/2008, financiado pela Fundação para a Ciência e a Tecnologia, Portugal.

Submetido em Junho de 2014. Aprovado em Novembro de 2014. 